\title{
Exérese de tumor incomum em região pré-auricular: relato de caso
}

Exerese of incomum tumor in preauricular region: case report

Exeresis del incomum tumoral en la región pre-auricular: relato de caso

Ellen Cristina GAETTI-JARDIM ${ }^{1}$

Daniella Moraes ANTUNES ${ }^{1}$

Rosana Mara Giordano de BARROS ${ }^{1}$

Francielly Thomas FIGUEIREDO ${ }^{1}$

Julio Cesar Leite da SILVA ${ }^{1}$

Elerson Gaetti JARDIM JÚNIOR ${ }^{2}$

Leonardo Perez FAVERANI ${ }^{2}$

Mario Eduardo BALDO ${ }^{3}$

${ }^{1}$ Universidade Federal de Mato Grosso do Sul (UFMS), Faculdade de Odontologia de Campo Grande (FAODO), 79070-900 Campo Grande-MS, Brasil

${ }^{2}$ Universidade Estadual Paulista (UNESP), Faculdade de Odontologia de Araçatuba, 16015-050 Araçatuba-SP, Brasil

${ }^{3}$ Mestre em Odontologia, Universidade Federal de Mato Grosso do Sul (UFMS), Faculdade de Odontologia de Campo Grande (FAODO), 79070-900 Campo Grande-MS, Brasil

\section{Resumo}

O cilindroma é um tumor de face raro que acomete frequentemente o couro cabeludo e o pescoço podendo ser benigno ou também desenvolver um curso maligno. É objetivo apresentar um caso de paciente de 55 anos de idade com um tumor de pequena dimensão em região pré-auricular a esquerda, com queixas álgicas e presença de discreta equimose. A terapêutica empregada foi a excisão cirúrgica e acompanhamento. A paciente, após 3 meses de controle pós-operatório apresenta-se sem queixas e sem sinais de recidiva. Deste modo, podese concluir que o tratamento empregado foi satisfatório com bons resultados. Em virtude da possibilidade de recidiva a paciente segue em acompanhamento.

Descritores: Cilindroma; Diagnóstico; Terapêutica.

\section{Abstract}

The cylindroma is a rare-face tumor that often affects the scalp and neck, which may be benign or develop a malignant course. The objective of this study is to present a 55-year-old patient with a small tumor in the preauricular region on the left, with painful complaints and a slight purpura. The therapy used was surgical excision and follow-up. The patient, after 3 months of postoperative control, presented with no complaints and no signs of relapse. In this way, it can be concluded that the treatment used was satisfactory with good results. Due to the possibility of recurrence, the patient is followed up.

Descriptors: Cylindroma; Diagnosis; Therapeutics.

\section{Resumen}

El cilindroma es un tumor de cara raro que acomete frecuentemente el cuero cabelludo y el cuello pudiendo ser benigno o también desarrollar un curso maligno. Es objetivo presentar un caso de paciente de 55 años de edad con un tumor de pequeña dimensión en región pre-auricular a la izquierda, con quejas álgicas y levemente enrojecida. La terapia empleada fue la excisión quirúrgica y seguimiento. La paciente, después de 3 meses de control postoperatorio se presenta sin quejas y sin signos de recidiva. De este modo, se puede concluir que el tratamiento empleado fue satisfactorio con buenos resultados. En virtud de la posibilidad de recidiva la paciente sigue en seguimiento.

Descriptores: Cilindroma; Diagnóstico; Terapéutica.

\section{INTRODUÇÃO}

Cilindroma é um raro tumor de pele e anexos que acomete sobretudo pescoço e couro cabeludo, com predominância para o sexo feminino e em idades mais avançadas. Pode ser benigno ou maligno, sendo este quando se relaciona a síndrome de BrookeSpiegler autossômica dominante $e^{1,2}$.

Suas características clínicas demonstram que podem variar de alguns milímetros a vários centímetros em tamanho sendo de nódulo único ou múltiplos e geralmente indolores e livre de parestesia em trajetos de nervos quando da apresentação benigna podendo em rarar situações ter transformação cancerígena e possibilidade de metástase ${ }^{3}$.

Inúmeros são os tipos de tratamento para o cilindroma há depender do grau de benignidade, tamanho e localização do mesmo. Pode variar de tratamento cirúrgico, altas doses de radiação bem como o uso do laser de dióxido de carbono e criocirurgia $^{1,4,5}$.

Sendo assim, é objetivo apresentar um caso de tratamento cirúrgico de cilindroma em região préauricular sob anestesia local.

\section{CASO CLÍNICO}

Paciente de 55 anos de idade procurou atendimento cirúrgico na Faculdade de Odontologia da Universidade Federal de Mato Grosso do Sul (Faodo - UFMS) queixando de dor em região próxima ao lóbulo da orelha esquerda, referindo já ter removido uma lesão na região há cerca de cinco anos cujo diagnóstico não se recordava. A anamnese a paciente refere não fazer uso de qualquer medicação diária nem possuir comorbidade sistêmica além de ausência de vícios e hábitos deletérios.

Ao exame clínico facial observou-se a presença de nódulo bem delimitado em região préauricular esquerda, dolorido a palpação, de cerca de 1 centímetro em seu maior diâmetro, de coloração levemente arroxeada, sendo tal característica compatível com o fato da paciente referir manipular a região constantemente. Ausência de exsudato purulento ou qualquer tipo de secreção glandular. Ao exame intrabucal nenhuma característica digna de nota foi observada, o mesmo ao exame de ortopantomografia.

Sendo assim, o diagnóstico inicial foi de cisto sebáceo/cisto a esclarecer e a paciente foi orientada a 
exérese da referida lesão sob anestesia local uma vez que a mesma se mostrava superficial. A paciente foi medicada com dexametasona $4 \mathrm{mg}$ via oral 01 hora antes do procedimento cirúrgico.

Após antissepsia da região pré-auricular com PVPI (polivinilpirrolidona iodo 10\%) tópico e aposição de campos estéreis, fez-se anestesia local circunferencial com mepivacaína $2 \%$, ao redor do referido nódulo com o cuidado de não mascarar as dimensões do mesmo. Após incisão cutânea com lâmina de número $15 \mathrm{c}$ montada em cabo de bisturi número 3, fez-se divulsão e descolamento por planos, completa exposição da lesão e exérese da mesma (Figura 1A a 1D) em seguida, hemostasia local e sutura intradérmica com nylon 5-0, sendo esta removida 5 dias após.
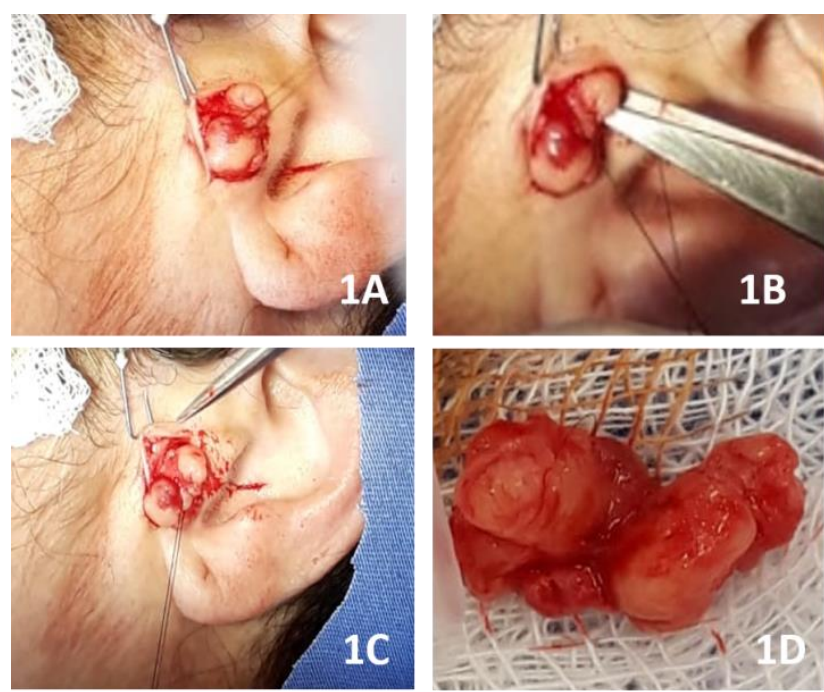

Figura 1A a 1C: Incisão, divulsão por planos e exposição de dois nódulos em região pré-auricular esquerda. 1D: dois nódulos removidos medindo cerca de 1 centímetro em seu maior diâmetro.

Ao exame macroscópico da peça removida, pode-se observar o aspecto endurecido da mesma e a divisão em dois lóbulos separados da glândula parótida que se encontrava preservada e sem envolvimento com a patologia removida.

$\mathrm{O}$ envio das peças para a análise histopatológica revelou neoplasia epitelial caracterizada pela proliferação de células basaloides, que se arranjam em ilhas e lóbulos. As células mais periféricas das ilhas, por vezes, mostram arranjo em paliçada, porém, as células mais centrais apresentam núcleo vesicular e citoplasma mais amplo e claro. Algumas dessas regiões centrais mostram semelhança com células secretoras sebáceas com pequenos corões de células neoplásicas infiltrando tecido adiposo e com disposição perivascular em periferia dos cortes com maior grau de pleomorfismo e hipercromatismo nuclear do que aquelas que estão compactadas na massa tumoral. Tendo deste modo, recebido o diagnóstico de cilindroma (Figura 2A a 2D).

A paciente está em acompanhamento pela equipe de cirurgia e traumatologia bucomaxilofacial da referida instituição há 3 meses e com orientação de equipe de cirurgia de cabeça e pescoço. A região operada apresenta bom aspecto das abordagens cirúrgicas e normalidade sem sinais de recidiva e a paciente sem queixas álgicas e/ou funcionais (Figura 3).
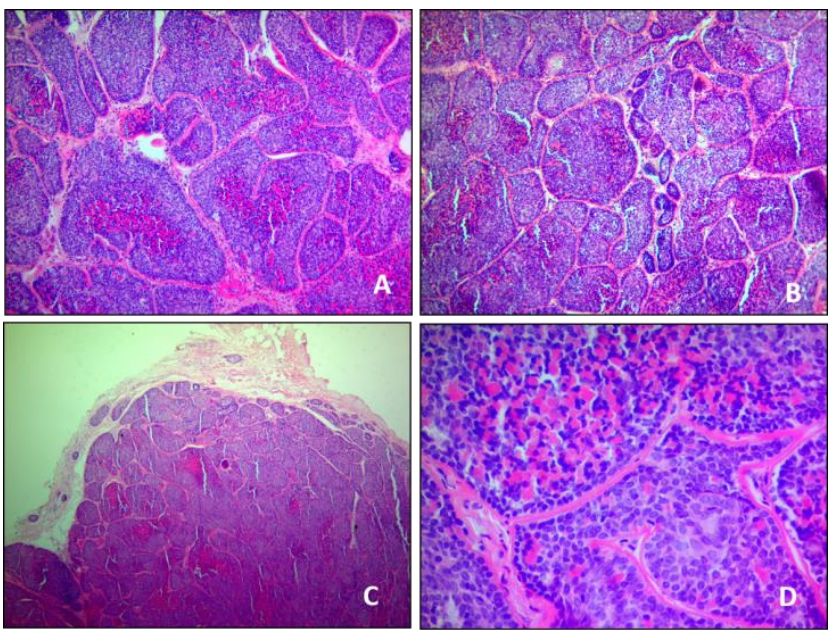

Figura 2A a D: Característica histopatológica. Espessa camada de membrana basal com produção de material hialino, diversos lóbulos em mosaico e células epiteliais dispostas em paliçada encapsulados por uma cápsula fibrosa externa

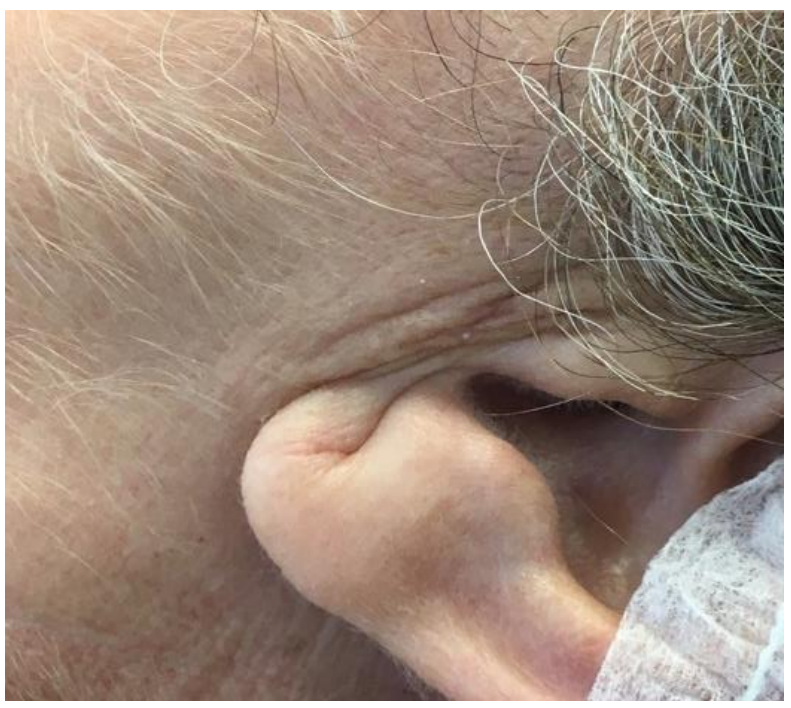

Figura 3: Bom aspecto da abordagem cirúrgica três meses após o procedimento.

\section{DISCUSSÃO}

A presença de uma patologia como o cilindroma não é uma rotina na clínica odontológica. Apesar das características de benignidade e o tamanho da lesão apresentada no caso acima, a mesma pode ter características que fogem o curso benigno sendo assim, necessitam de atenção e cuidado.

O cilindroma é geralmente encontrado em região de couro cabeludo e pescoço o que faz o relato deste caso ser interessante uma vez que o mesmo apresentou-se em região pré-auricular, ${ }^{1,6}$.

O tratamento cirúrgico, como demonstrado pela literatura, sobretudo em casos de pequenas 
dimensões, é a terapêutica de escolha. Fato este que corrobora o tratamento empregado, demonstrando até o momento, resultados satisfatórios.

Em razão de a paciente ter relatado remoção de lesão em mesmo local há cinco anos, e a literatura embasar esse evento, apresentando índices consistentes de recidiva da lesão ${ }^{7}$, a paciente segue em acompanhamento pela equipe e orientação pelo médico cirurgião de cabeça e pescoço, em virtude do potencial de transformação maligna ${ }^{8}$.

CONCLUSÃO

A raridade do cilindroma em uma clínica de graduação em odontologia chama atenção e deste modo a terapia instituída reveste-se de importância que gerou resultados satisfatórios para a paciente assim como no aprendizado para os alunos.

\section{REFERÊNCIAS}

1. Singh DD, Naujoks C, Depprich R, Schulte K, Jankowiak F, Kübler NR et al. Cylindroma of head and neck: Review of the literature and report of two rare cases. J Craniomaxillofac Surg. 2013; 41(6):516-21.

2. Sicinska J, Rakowska A, Czuwara-Ladykowska J, Mroz A, Lipinski M, Nasierowska-Guttmejer A et al. Cylindrom a transforming into basal cell carcinoma in a patient with Brooke-Spiegler syndrome. J Dermatol Case Rep. 2007;1(1):4-9.

3. Mourouzis C, Boynton A, Grant J, Umar T, Wilson A, Macpheson D et al: Cutaneous head and neck SCCs and risk of nodal metastasis e UK experience. J Craniomaxillofac Surg. 2009;37(8): 443-47.

4. Retamar RA, Stengel F, Saadi ME, Kien MC, Della Giovana P, Cabrera $\mathrm{H}$ et al: BrookeSpiegler syndrome e report of four families: treatment with CO2 laser. Int J Dermatol. 2007; 46(6):583-86.

5. Schmaltz R, Muller CS, Vogt T. Sudden growth of previously indolent scalp nodule. Hautarzt. 2010;61(6):518-21.

6. Jordão C, de Magalhães TC, Cuzzi T, Ramos-eSilva M. Cylindroma: an update. Int J Dermatol. 2015;54(3):275-78.

7. Bansal C, Batra M, Lal N, Srivastava AN. Solitary Cylindroma with Malignant Transformation. Indian J Dermatol. 2012;57(2):141-43.

8. Gerretsen AL, van der Putte SC, Deenstra W, van Wloten WA.Cutaneous cylindroma with malignant transformation. Cancer. 1993; 72(5):1618-23.

\section{CONFLITO DE INTERESSES}

Os autores declaram não haver conflitos de interesse.

AUTOR PARA CORRESPONDENCIA

\section{Ellen Cristina Gaetti Jardim}

ellengaetti@gmail.com

Submetido em 05/02/2019

Aceito em 16/03/2019 